\title{
A Corpus-based Linguistic Analysis of Latin Frequentative Verbs
}

\section{Cover Page Footnote}

This paper was originally completed as part of the University of Colorado Department of Linguistics preliminary examination doctoral requirement, submitted to the preliminary examination committee on October 1, 2015 and passed on December 3, 2015. I would like to thank Dr. Laura Michaelis for helping develop and problematize the introduction of this paper. 


\title{
A CORPUS-BASED LINGUISTIC ANALYSIS OF LATIN FREQUENTATIVE VERBS
}

\author{
JARED DESJARDINS
}

\section{University of Colorado Boulder}

\begin{abstract}
Considering that Latin FREQUENTATIVE verbs have transparent morphological structure (the supine stem of the base verb concatenated with the frequentative -itare suffix and regular first conjugation inflectional endings), one would assume that the meaning of each such verb is related in a predictable way to that of its corresponding base verb, and that all members of the frequentative class share semantic entailments. However, frequentative verbs resist a uniform semantic analysis and can mean something entirely unpredictable from the sum of their parts, and traditional and contemporary definitions of frequentatives ignore the degree of idiomaticity between frequentative form and function and are based on limited corpus data. This paper provides a synchronic, corpus-based linguistic analysis of frequentative verbs in comparison to their base forms from both derivational (source-oriented) and usage-based (product-oriented) perspectives in order to explore the nature of the Latin frequentative. The paper concludes that a usage-based, product-oriented treatment of the data provides a more straightforward characterization of Latin frequentative verbs, highlighting the interconnectedness of morphology, syntax, and semantics.
\end{abstract}

Keywords: morphology, syntax, semantics, corpus linguistics, Latin

\section{INTRODUCTION}

FREQUENTATIVE (FV) verbs (from Latin frequentare 'to repeat often') comprise a class of Latin verbs classically characterized as denoting forcible or repeated action, as in the case of pulsare 'beat repeatedly', from pellere 'beat'. A salient feature of the Latin lexicon, FV forms survive in the etymologies of learned English borrowings (e.g., inhabitant, fluctuate, agitate) and as a shared inheritance of Romance languages, in numerous reflexes of Latin FV lexemes: Italian cacciare 'hunt', from the FV form of Latin capio 'catch', French raser 'shave', from the FV form of Latin radere 'scrape', and Spanish cantar, from the FV form of Latin canere 'sing' (Solodow 2010:151-153). The Latin FV template is both highly productive and transparent, representing a straightforward instance of concatenation: FVs are formed by first-conjugation inflection of the supine (passive-participial) stem of the base verb (Greenough et al. 2001:152). While FVs are formed from all three Latin verb conjugations, the derived FVs are exclusively first conjugation (and exhibit first conjugation morphology), as illustrated by rogitare (derived from first conjugation rogare 'ask'), habitare (derived from second conjugation habere 'have') and cursare 
(derived from third conjugation currere). A survey of FV instances in the classical corpus (comprising Latin works from the $100 \mathrm{BCE}$ to $100 \mathrm{CE}$ period) shows that the FV pattern is widely attested across that particular Latin lexicon. The pattern's internal transparency and high type frequency suggests that its semantic effect is equally transparent - that the FV derivation modulates the base verb's semantic representation in a predictable and uniform way. It is immediately apparent, however, that the traditional account of FV meaning is inadequate; while some FV predications do express repeated actions, or actions performed with unusual force, many do not. The FV habitare, for example, is derived from a state verb (habere 'to have, hold'), and does not indicate repeated episodes of having. Instead, it typically denotes 'holding' a piece of real estate, or inhabiting a house, as demonstrated in 1:

(1) et Cn. Servilio praetori urbano negotium datum ut Campani cives, ubi cuique ex senatus consulto liceret habitare, ibi habitarent, animadverteretque in eos qui alibi habitarent

'additionally Cnaeus Servilius, the city praetor, was to see that the Campanian citizens were living where the senate allowed them to live, and he was to punish those living elsewhere' (Liv. 28.46)

Example 1 is an account of Cnaeus Servilius's duties as City Praetor, an elected government position in which he is to oversee that the citizens of Capua are living only where the Senate decrees and punish those who reside elsewhere. Livy's use of habitarent is in the context of the Senate's orders to Servilius and his responsibilities as City Praetor and Servilius's obligations to manage Capua's residential laws. A traditional FV interpretation of habitarent in 1 is problematic, since a reading in which the Capuan citizens repeatedly engage in states of 'having' is inconsistent with the context set up by Servilius's position as City Praetor, and his orders to enforce land ownership and residential restrictions. Instead a more idiomatic interpretation of residing or inhabiting a house for habitarent is preferred, since 'residing in/inhabiting a house' can be seen as a metaphorical extension of the base verb habeo's basic meaning of 'having'.

Considering FV verb lexemes tend to be highly polysemous, which follows from the productivity of the FV template in the language, and that the meaning of a FV verb is often unpredictable in relation to its 'base' verb lexeme's semantics (since new meanings are known to replace the original FV sense) the traditional grammatical treatment raises questions concerning what it means to be a FV, and how that verb class can be characterized in Latin. To augment the 
repertoire of notions traditionally associated with FV meaning, modern authors including Viti (2012) have characterized FVs as expressing "emphasis or expressivity" (p. 1). One can generalize this characterization to one that applies to those instances in which FVs express actions performed in unusual ways. One such instance is given in 2:

$$
\begin{array}{llllll}
\text { singula } & \text { verba } & \text { vellenti tamquam dictaret } & \text { non diceret } \\
\text { single } & \text { words } & \text { plucking as if } & \text { dictate not speak }
\end{array}
$$

'when Vinicius was dragging out his words one by one, as if he were dictating, not speaking' (Sen. Ep. 40)

Example 2 is a passage from one of Seneca's letters to Lucilius, in which the author is discussing the proper style for a philosopher's speech and communication. Here Seneca recommends that Lucilius not concern himself with the criticism of those who care more about the volume of output than the manner in which it is conveyed and suggests Lucilius speak as Publius Vinicius 'the stammerer' speaks. The passage offers a contrast between the canonical mode of speaking, denoted by diceret and a hyperarticulate mode of speaking expressed by dictaret.

The repertoire of possible FV meanings can therefore be seen as including more figurative variants of both their base verb's semantics as well as the semantics associated with the derived $\mathrm{FV}$, lending themselves more readily to be used creatively and in novel contexts and environments (both in terms of the formal characteristics of their distribution(s), as well as their use in different semantic and pragmatic contexts). This is supported by the observation that FV verbs are numerous in comedy (Viti 2012:1). In other words, Viti (2012:2) contests the classical assumption by contrasting the a priori traditional definition of the repeated, intensive FV interpretation with what she claims to be the FV derivation's primary function of emphasis and expressivity as a strategy to express imperfective (either progressive or habitual) aspect and backgrounded information (particularly when taken into consideration with Proto-Indo European's historical aspectual system paradigm).

However, even Viti's broadened definition fails to apply to the wide array of FV forms. For example, Viti's labels of 'emphasis' and 'expressivity' are highly subjective, limiting the explanatory and predictive power that would follow from an operationalized, synchronic analysis utilizing formalized linguistic features. Furthermore, even Viti's proposed expanded repertoire of 
FV meanings fails to include a majority of highly idiomatic FV interpretations, as in examples 3 and 4:

domin-us Callist-um vendidit

master-NOM Callistus-ACC sell

'the master sold Callistus' (Sen. Ep. 47)

$\begin{array}{lllll}\text { Quint-us } & \text { frater } & {[\ldots] \text { Tusculan-um }} & \text { venditat } & \text { ut ... } \\ \text { Quintus-NOM } & \text { brother.NOM } & {[\ldots] \text { Tusculan.property-ACC }} & \text { sell } & \text { so.that... }\end{array}$

'my brother Quintus is now trying to sell his Tusculan property, in order to purchase, if he can, the townhouse of Pacilius' (Cic. Att. 1.14)

In 3, Seneca is recalling how much more Callistus's former master lost in comparison to his gains in selling Callistus. Seneca ends by saying dominus Callistum vendidit 'the master sold Callistus [but how much has Calllistus made (his master) pay for!]', a standard transitive use of the base verb vendidit 'he sold'. In 4, Cicero is telling Atticus, a close friend, that his brother Quintus is trying to sell his Tusculan property. The emphatic, intensive action can be inferred from the fact that the selling action (venditat) introduces a purpose clause (headed by the conjunction $u t$ ): so that he (Quintus) can purchase a townhouse he desires. However, both a traditional as well as an emphatic/expressive (cf. Viti 2012) interpretation result in inadequate translations, since the use of venditare in 4 is not only an intensive form of 'selling', but a very specific form of 'selling property'.

Given that FVs resist a uniform semantic analysis and that any FV can mean something entirely unpredictable from the sum of its parts, and traditional and contemporary (Viti 2012) FV definitions ignore the degree of idiomaticity between FV form and function (and are based on limited corpus data), this paper therefore provides a synchronic, corpus-based linguistic analysis of FV verbs in comparison to their base forms from both derivational (SOURCE-ORIENTED) and usage-based (PRODUCT-ORIENTED) perspectives (Bybee 2001:126) in order to explore the nature of the Latin FV 'derivation'. To do so, I analyze 15 tokens of each FV and corresponding base verb for the top nine most frequent FV lexemes (totaling $135 \mathrm{FV}$ and base verb tokens; 270 verb tokens total), in terms of their morphological, syntactic, and semantic properties. The remainder of this paper is organized as follows: in section 2 I outline the procedure and methodology in acquiring the Latin FV data and corpus development, and the subsequent linguistic analysis of 
each verb token. In section 3 I present and discuss the results of the linguistic analysis and provide a summary and concluding remarks in section 4 .

\section{METHODOLOGY AND ANALYSIS}

\subsection{CORPUS DATA}

The present analysis utilizes a Latin data corpus (currently in development) in order to locate any and all possible FV verb forms. First, the entire collection of the Latin Perseus Digital Library (Crane 2005) (provided under the Creative Commons ShareAlike 3.0 license) was downloaded as individual extensible markup language $(. \mathrm{xml})$ files. Since the Latin text in each .xml file was encoded in a machine-readable format, a Python program was developed to extract all Latin text, which was then written to individual text (.txt) files. Once the Latin .txt files were generated, a subsequent program was created to clean, format, and normalize the Latin text, addressing the following considerations:

- Each generated .txt file contained various xml and html (hypertext markup language) encodings. Therefore, a function was implemented which removed all remaining $\mathrm{xml}$ or html encodings, while leaving any Latin text unchanged.

- Due to the frequency of Roman dates (e.g. Prid. Id. Mart. = Pridie Idus Martias = March 14), Roman Numerals (e.g. LXVII $=67$ ), and Roman name abbreviations ${ }^{2}$, a separate function identified each (and their various forms) in order to treat them as proper constituents.

- Another common occurrence in Latin text concerns the orthographic representation of the phonemes /j/ and /w/. For example, the verb /'jakio/ 'I throw' might be written as iacio or jacio. Similarly, the noun /'serwus/ 'slave' might be represented as servus or seruus. Therefore, the data was normalized so that the Latin phonemes $/ \mathrm{j} /$ and /w/ were uniformly represented by the same grapheme ( $\langle i\rangle$ and $\langle u\rangle$, respectively).

- Finally, the Latin data was generally formatted, addressing concerns such as capitalization and punctuation, and a new .txt file corresponding to each Latin author and particular text (e.g. Caesar: De Bello Gallico 'On the Gallic War') was generated, producing the entire raw text Latin corpus.

\footnotetext{
${ }^{2}$ It was common in Latin literature to abbreviate one's praenomen, or first name, as in C. (Gaius) Julius Caesar and M. (Marcus) Tullius Cicero.
} 
Since the present study considers FV verbs from the Golden Age of Latin (approximately 70 BCE - $18 \mathrm{CE}$ specifically), the corpus was partitioned based on authors who were active during that time period. At the time of writing, the Golden Age Latin subcorpus consists of 16 authors (from Caesar to Vergil) and $157,860^{3}$ tokens.

Once the Latin Golden Age subcorpus was sufficiently prepared, a final program was written in order to: (1) locate any and all possible FV verb forms, (2) generate separate results files containing each FV token and textual context, and (3) return the token frequency of each FV verb. Since the derived FV verb form is invariably first conjugation, regardless of the conjugation class of the base verb, certain morphological information was taken into consideration in the detection process. As the program iterated over each token, it 'checked' whether the token is a first conjugation verb, based on predictable first conjugation verbal morphology (specifically, the presence of the vowel $a$ in the verb stem), and whether the FV -it suffix immediately follows the verb root and immediately precedes any inflectional morphology, as in 5:

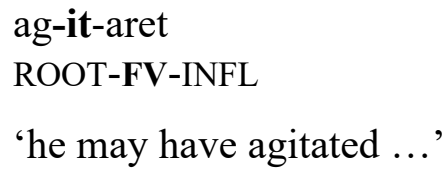

After the FV tokens were located, a randomizing function was called shuffling the FV data. Results files were generated containing a random sample of $15 \mathrm{FV}$ tokens for the top nine most frequent FV verb lexemes (including the token, context, and author and source for each).

\subsection{PROCEDURE AND ANALYSIS}

I consider three levels of linguistic abstraction in my analysis - morphology, syntax, and semantics - and how those levels interact with respect to Latin FVs and their base verbs. The proceeding subsections outline the specific morphological, syntactic, and semantic features noted for each verb token.

\footnotetext{
${ }^{3}$ This figure is a best approximation and will be finalized as the corpus is further developed.
} 


\section{MORPHOLOGICAL PROPERTIES}

Two morphological characteristics were noted in the annotation of each FV and base verb token: GRAMMATICAL VOICE, and whether the token was a base or DERIVED (i.e. FV) form. The grammatical voice of the token was determined by the presence of active or passive verbal morphology, which is largely systematic and predictable in $\mathrm{Latin}^{4}$, in conjunction with recognized syntactic properties of passivization, such as demotion of the ACTOR from the nominative case to an oblique (typically ablative, or a prepositional phrase if syntactically realized), and promotion of the UNDERGOER from the accusative case to nominative (Dixon and Aikhenvald 2011). Additionally, as noted in section 2.1, the derived form was determined based on the transparent morphological structure of the FV relative to its base verb form (i.e., the presence of the -it FV morpheme and first conjugation morphology).

\section{SYNTACTIC PROPERTIES}

In addition to word-level properties, I consider three syntactic properties: verb VALENCY, the syntactic FRAME (and syntactic restrictions), and the number of syntactically realized PROTOAGENTS and PROTO-PATIENTs. Verb valency was determined by the number of arguments present in the sentence or clause that are semantically necessary to the proposition expressed by that verb. For example, in example 6 the arguments needed to 'complete' the verbal action are hic 'that man' (AGENT), patriam 'country' (THEME), and auro 'for gold' (ASSET), indicating that this verb token vendidit has a valency of three.

$$
\begin{aligned}
& \text { vendidit hic } \begin{array}{ll}
\text { aur-o } & \text { patri-am } \\
\text { sell that.NOM } & \text { gold-DAT } \\
\text { country-ACC }
\end{array} \\
& \text { 'that traitor sold his country for gold' (Verg. A. 6.621) }
\end{aligned}
$$

Syntactic frames were modeled on those utilized in the VerbNet (Kipper-Schuler 2005) verb lexicon and were considered in the present analysis with the hypothesis that syntactic frames can correlate with semantic class membership (Levin 1993), in the same sense as VerbNet. An example syntactic frame might be [NP[nom] V NP[acc] NP[dat]] for 6 above (the syntactic frames' word

\footnotetext{
${ }^{4}$ With the exception of deponent and semideponent verbs, which are morphologically passive but syntactically and semantically active.
} 
order reflects English's for the purpose of analysis, mirroring the syntactic representations in VerbNet, but with the awareness that word order is flexible in Latin and is not used to track grammatical relations). In cases where the syntactic subject had been 'dropped' (facilitated by subject agreement morphology on the verb), a PRO constituent was provided in the syntactic frame. Additionally, restrictions were included on each syntactic constituent as subcategorization information, reflecting information such as:

- The specific case argument NPs appeared in (e.g. NP[nom] for nominative, NP[dat] dative).

- Voice for passivized verbs (e.g. NP[nom] V.pass).

- The specific preposition heading PPs (e.g. PP[ex] for 'out of...', PP[ad] for 'toward...').

- The sentential complement type (e.g. S[inf] for a bare infinitive, S[cx] for a syntactic construction).

Finally, quantitative figures were collected for the number of syntactically realized protoagents and proto-patients (introduced below) for each FV and base verb lexeme, since the overt realization of proto-agents and proto-patients can be seen to reflect the degree of transitivity of the verb - an overt (individuated) subject is typically more agentive (and nonindividuated as less agentive), and an overt object is typically more physically affected (and nonindividuated is less physically-affected) (Hopper and Thompson 1980:252).

\section{SEMANTIC PROPERTIES}

At the highest level of abstraction, in the sense that the morphological and syntactic properties tend to be physically instantiated and directly observable, certain semantic properties were considered: SEMANTIC ROLE ARRAY (and selectional restrictions), VERBNET SEMANTIC CLASS, and the number of agentive PROTO-AGENTs and physically affected (or having undergone changes in state) PROTO-PATIENTs.

I assume the same set of semantic roles as those used in VerbNet (Kipper-Schuler 2005), and in order to facilitate any potential semantic generalizations, these fine-grained semantic roles (e.g. agent, stimulus, experiencer, theme, patient, etc.) were also considered in terms of their classification into Dowty's (1989) two 'macro-roles': proto-agent (PAG) (expressing volition, sentience, causation, etc.) and proto-patient (PPT) (change of state, causally affected, etc.). Furthermore, for each semantic role certain selectional restrictions were noted in a similar fashion 
to VerbNet, such as whether the role(s) require a $+/$ - animate argument. However, I consider one additional selectional restriction as an additional measure of overall transitivity: whether the verbal arguments are $+/$ - referential, in the strict semantic sense that the argument is + referential if it denotes an individual or property in the world (Kearns 2011:2). This additional semantic feature can therefore be seen as reflecting the degree to which that argument is truly agentive (PAG) or physically affected (PPT) (Hopper and Thompson 1980:252).

In addition, I mapped each verb token to an existing VerbNet semantic class (VNC), in order to generalize across several related and potential interpretations of that particular token, as well as to assist in the determination of the token's semantic role array. In certain ambiguous cases, the possible English senses of the token were located in the Proposition Bank (PropBank) (Palmer et al. 2005) English framesets index, and the VNC was then determined through the mapping between PropBank and VerbNet, facilitated by the Unified Verb Index ${ }^{5}$. Finally, quantitative figures were calculated reflecting several semantic effects of the FV derivation, such as the number of agentive PAGs, physically affected PPTs, +/- referential PAGs, +/- animate PPTs, etc.

\section{RESULTS}

Results of the linguistic analysis demonstrate that while some linguistic features are unhelpful in attempting to characterize the Latin FV verb, such as the number of valent members and passive or active morphology, other syntactic and semantic properties do appear to be helpful, albeit to varying degrees and depending on whether a derivational or usage-based perspective is assumed. In section 3.1 I discuss possible derivational generalizations, followed by a discussion of the usagebased generalizations in section 3.2.

\subsection{DERIVATIONAL CHARACTERIZATIONS}

From a strictly derivational perspective, no clear semantic generalization was able to be formed in regard to the semantic class membership of Latin FV verbs. However, the application of the FV -it suffix does appear to affect particular semantic properties in a general manner, primarily concerning the PAG, PPT, and potentially the transitivity of the derived FV form.

\footnotetext{
${ }^{5}$ The Unified Verb Index merges information from four natural language processing projects: VerbNet, PropBank, FrameNet, and OntoNotes Sense Groupings. Online: https://verbs.colorado.edu/verb-index/index.php.
} 


\section{EFFECTS ON PAGS}

The FV derivation seems to disfavor referential PAGs in comparison to their base verb semantics, however this generalization is slightly variable. For example, the derived FV verb form CIT (represented by its root) was observed to occur only twice with a referential PAG and 13 times with a nonreferential PAG compared to its base verb $\mathrm{CI}(\mathrm{E})$, whose occurrence is more evenly distributed between referential and nonreferential PAGs: nine times with a referential PAG, and six times with a nonreferential PAG (a full table reflecting these figures is provided in Table 1 in the Appendix). Examples 7 and 8 illustrate this:

$$
\begin{array}{llll}
\text { latin-us } & \text { dux } & {[\ldots] \text { proeli-um }} & \text { ciet } \\
\text { Latin-NOM } & \text { leader.NOM } & {[\ldots] \text { battle-ACC }} & \text { urge }
\end{array}
$$

'the Latin leader [not the least discouraged by his wounds] urged on the fighting' (Liv. 2.19)

(8) labor optim-os citat

labor.NOM best-ACC call

'work calls for the best men' (Sen. Prov. 1.5)

In 7, Livy is recounting in his History of Rome an intense battle among several soldiers, and our example occurs just as the Latin leader is injured and withdraws from the battle. The PAG latinus $d u x$ 'Latin leader' is syntactically realized, clearly referential, and functions as the subject to the base verb CIE. In contrast, although also syntactically realized, the PAG in 8 is largely nonreferential, in that it expresses a highly abstract concept 'labor; work; toil'. The PAGs of the derived $\mathrm{FV}$ forms tend to be in general nonreferential and less potent in their agency, indicating a lower degree of transitivity (Hopper and Thompson 1980:252). Therefore, a preliminary conclusion concerning the derivational effects of the FV suffix might be the reduction in agency and transitivity of the derived lexeme, considering approximately $73 \%$ of all $\mathrm{FV}$ forms sampled occur with nonreferential PAGs (cf. Table 1) in contrast with an approximately even distribution of base verb forms occurring with referential and nonreferential PAGs.

\section{EFFECTS ON PPTS}

FV derivational effects on PPTs were similar to those on PAGs; specifically, the derived verbs seem to prefer nonreferential PPTs, with approximately $40 \%$ of FVs occurring with nonreferential PPTs as opposed to approximately $34 \%$ of base forms occurring with nonreferential PPTs (cf. 
Table 1). However, derivational effects on PPTs appear to be more uniform, and in general seem not to result in a change of state or take a physically affected PPT. For example, the FV HABIT never occurred with referential PPTs or physically affected PPTs, compared to its base verb HAB, which was observed to occur eight times with a physically affected PPT and 11 times with a referential PPT. Similarly, the FV VENDIT was observed to occur only three times with a physically affected PPT and once with a referential PPT, whereas its base verb VEND occurred 14 times with a physically affected PPT, and 13 times with a referential PPT. These effects of the FV derivation on PPTs are also apparent between the FV and base verb pair COGIT and COG, as shown in 9 and 10 :

$$
\begin{array}{llll}
\text { eos } & \text { ipsos } & {[\ldots] \text { ced-ere }} & \text { in tutm coegit } \\
\text { PRO.MASC.PL.ACC } & \text { those-MASC.PL.ACC } & {[\ldots] \text { withdraw-INF into safety force }}
\end{array}
$$

'he forced/compelled them to withdraw to a place of safety' (Liv. 2.10)

$$
\text { nihil de resistendo cogitabat }
$$

nothing.ACC concerning resisting consider

'they (inferred Attinian army) never thought of making resistance' (Caes. Civ. 2.34)

It is important to note that, similar to the FV HABIT, the FV COGIT never takes a physically affected or referential PPT, whereas its base COG almost exclusively does. Example 9 occurs as Livy recounts an attack on Rome, and how one individual, Horatius Cocles, had been able to prevent the onslaught. The PPT ipsos eos 'those individuals (masculine plural)' is referential, referring to a group of individuals (Roman citizens), and evidently undergoes a change of state, being the object in an object control construction in which the PPT is the syntactic object of the control verb (coegit 'force') and the syntactic subject of the subordinate infinitival cedere 'withdraw'. Furthermore, the subordinate action of 'withdrawing' involves a change in location, further highlighting the change of state of the PPT ipsos eos. The FV cogitabat 'consider' in 10 takes a nonreferential PPT (nihil de resistendo 'nothing concerning resisting'), and is neither physically affect nor undergoes a change of state. Analogous to the prior observation concerning the FV derivation's effects on PAGs, the tendency of FVs to take nonreferential, nonphysically affected PPTs suggests reduction in transitivity to be a result of the application of the FV suffix, as well as a reduction in agency of the PAG. 


\subsection{USAGE-BASED CHARACTERIZATIONS}

In contrast to a derivational (or source-oriented (Bybee 2001:126)) approach, which attempts to specify the base verb form and a single operation with a single set of conditions (Croft and Cruse 2004:301) (in this case, the application of the FV -it suffix and the attempt to predict and generalize over its semantic effects), FVs can be investigated in terms of "conditions" on the FV form only (Becker and Fainleib (2009:3). When viewed in terms of a usage-based, or product-oriented (Bybee 2001:126), the semantic classification of FV tokens appear to be influenced by their syntactic frames, semantic role array, and particular lexemes appearing in their argument complementation.

\section{FRAMES, ROLES, AND VNC MEMBERSHIP}

Examples 11 and 12 illustrate the relationship between VNC membership and particular syntactic frames and semantic roles:

cum se cogitat esse pi-um

ADV himself.ACC consider be.INF pious-ACC

'when he knows that he is pious' (lit. 'considers himself to be..') (Catul. 76)

$$
\begin{aligned}
& \text { sed }[\ldots] \text { cogitavit }[\ldots] \text { reg-es barbar-os incit-are } \\
& \text { CONJ }[\ldots] \text { plan } \quad[\ldots] \text { ruler-ACC foreign-ACC incite-INF } \\
& \text { 'but he planned [from the start] [...] to incite foreign rulers' (Cic. Att. 8.11) }
\end{aligned}
$$

The frame [PRO V NP[acc] NP[inf]] in 11 exclusively occurred with the 'consider, know' interpretation of the FV COGIT correlating with the CONSIDER-29.9 class, as matched to VerbNet. Furthermore, the semantic role theme also only occurred with the CONSIDER-29.9 class, indicating a relation between the semantic role(s) of the FV verb's core arguments and its semantic class membership. In comparison, the syntactic frame [PRO V S[inf]] exhibited in 12 exclusively occurred with the 'plan, intend' interpretation of COGIT, correlating with the WISH62 semantic class (its closest match in VerbNet).

\section{LEXICAL COMPLEMENTATION AND VNC MEMBERSHIP}

Another structural feature that tended to correlate with FV's VNC membership concerns particular lexemes appearing in the complementation of the verb, as demonstrated in 13 below: 
(13) et defendend-ae urb-is consili-a agitaba-ntur CONJ defending-GEN city-GEN plans-NOM discuss-PASS

'plans of defending the city were discussed' (Liv. 10.21)

Semantically, the FV AGIT in Example 13 might belong to nine ${ }^{6}$ possible VNCs. However, the lexeme consilia 'plans, counsel' (and a related lexeme res 'thing, event, fact') only occurred with the DISCUSS interpretation (and VNC classification) of AGIT. A similar relationship was observed among the FV VENDIT sample: when the PPT being 'sold' is the reflexive pronoun se 'oneself', coindexed with the PAG, the interpretation of AGIT is exclusively INGRATIATE - a metaphorical extension, considering the literal translation as 'sell oneself'. It is interesting to note that these highly metaphorical, idiomatic interpretations, and particular lexical complementation patterns, tend to occur with lower frequency FV lexemes (e.g. FLAGIT (90 token frequency), VENDIT (54), and DICT (46)), compared to higher frequency FVs such as COGIT (748); this will be explored in future work.

\section{CONCLUDING REMARKS}

This study considered certain morphological, syntactic, and semantic properties of Latin FV verbs from two synchronic perspectives: derivational (source-oriented) and usage-based (productoriented). In attempting to characterize the FV as a derivational process, the FV -it suffix appears to affect whether the derived verb's PAG and PPT are referential, tending to take non-referential core arguments in relation to their base verb forms, and unaffected PPTs. This can be viewed as a reduction transitivity and agency (Hopper and Thompson 1980), which follows from FVs' denominal origins (Greenough et al. 2001:152) with denominal verbs typically denoting a state (Viti 2012:7) and low transitivity. The FV derivation can therefore be seen as a potential stativizing

${ }^{6}$ The possible VNCs to which the FV AGIT might belong, as identified in this study, include:

1. DISCUSS (no VerbNet equivalent, sense from PropBank)

2. AMUSE-31.1

3. ESTABLISH-55.5-1

4. CONDUCT (no VerbNet equivalent, sense from PropBank)

5. HANDLE (ibid.)

6. FORCE-59

7. JUDGEMENT-33

8. PUSH-12-1-1

9. RISK-94 
process as reflected by its argument selection and overall reduction in transitivity. In contrast, a usage-based, product-oriented analysis reveals that specific syntactic frames, semantic roles, and lexical complementation allows FV lexemes to be clustered in terms of PROTOTYPICAL semantic classes, providing a more straightforward characterization of Latin FV verbs and highlights the interconnectedness of morphology, syntax, and semantics.

\section{REFERENCES}

Becker, Michael, and Lena Fainleib. 2009. The naturalness of product-oriented generalizations. Amherst, University of Massachusetts Amherst, MS. Online: http://www.phonologist.org/hebrewplurals/.

Bybee, Joan. 2001. Phonology and language use. Cambridge: Cambridge University Press.

Crane, Gregory R. (ed.) 2005. Perseus Digital Library. Medford, Tufts University. Online: http://www.perseus.tufts.edu.

Croft, William, and D. Alan Cruse. 2004. Cognitive linguistics. Cambridge: Cambridge University Press.

Dixon, R. M. W., and Alexandra Aikhenvald. 2011. A typology of argument-determined constructions. In Language at large: Essays on syntax and semantics. Leiden: Brill.

Dowty, David R. 1989. On the semantic content of the notion 'thematic role'. In Gennaro Chierchia; Barbara H. Partee; and Raymond Turner. (eds.) Properties, Types and meaning, II. Dordrecht: Kluwer Academic Publishers.

Greenough, J. B.; G. L. Kittredge; A. A. Howard; and Benj. L. D'ooge. (eds.) 2001. Allen and Greenough's new Latin grammar. Newburyport: Focus Publishing, R. Pullins \& Company. Hopper, Paul J., and Sandra A. Thompson. 1980. Transitivity in grammar and discourse. Language 56.251-299.

Kearns, Kate. 2011. Semantics. New York: Palgrave Macmillan.

Kipper Schuler, Karin. 2005. VerbNet: A broad-coverage, comprehensive verb lexicon. Philadelphia: University of Pennsylvania dissertation.

Levin, Beth. 1993. English verb classes and alternations: A preliminary investigation. Chicago: University of Chicago Press.

Palmer, Martha; Daniel Gildea; and Paul Kingsbury. 2005. The Proposition Bank: An annotated corpus of semantic roles. Computational Linguistics 31 . 
Solodow, J.B. 2010. Latin alive: The survival of Latin in English and the Romance languages. Cambridge: Cambridge University Press.

Viti, Carlotta. 2012. The use of frequentative verbs in Early Latin. Proceedings of the XVI Colloquium Internationale Linguisticae Latinae, Uppsala. 
APPENDIX - TABLE 1. FV AND BASE VERB QUANTITATIVE FIGURES

\begin{tabular}{|c|c|c|c|c|c|c|c|c|}
\hline $\begin{array}{l}\text { FV } \\
\text { BASE }\end{array}$ & Token Freq. & VNCs & $\begin{array}{l}\text { Overt } \\
\text { PAGs }\end{array}$ & $\begin{array}{l}\text { Overt } \\
\text { PPTs }\end{array}$ & $\begin{array}{c}\text { Transitive/ } \\
\text { Agentive PAGs }\end{array}$ & $\begin{array}{c}\text { Phys. } \\
\text { Affected } \\
\text { PPTs }\end{array}$ & $\begin{array}{l}\text { PAGs } \\
+/ \text { - ref. }\end{array}$ & $\begin{array}{l}\text { PPTs } \\
\text { +/- ref }\end{array}$ \\
\hline AGIT & 362 & 9 & 2 & 14 & 0 & 2 & $1 / 14$ & $2 / 13$ \\
\hline $\mathrm{AG}$ & & 6 & 3 & 12 & 2 & 4 & $7 / 3$ & $5 / 10$ \\
\hline CIT & 427 & 3 & 4 & 14 & 10 & 2 & $2 / 13$ & $12 / 3$ \\
\hline $\mathrm{CI}(\mathrm{E})$ & & 2 & 9 & 15 & 11 & 15 & $9 / 6$ & $11 / 4$ \\
\hline COGIT & 748 & 2 & 6 & 13 & 10 & 0 & $4 / 11$ & 0 \\
\hline $\mathrm{COG}$ & & 1 & 2 & 9 & 11 & 15 & $4 / 11$ & $10 / 5$ \\
\hline CONCIT & 278 & 1 & 4 & 14 & 8 & 15 & $5 / 10$ & $11 / 4$ \\
\hline CONCI(E) & & 1 & 9 & 15 & 15 & 15 & $6 / 9$ & $10 / 5$ \\
\hline DICT & 46 & 1 & 6 & 12 & 15 & 15 & $3 / 12$ & $8 / 7$ \\
\hline DIC & & 4 & 6 & 15 & 11 & 4 & $7 / 8$ & $9 / 6$ \\
\hline EXCIT & 311 & 3 & 7 & 14 & 12 & 15 & $5 / 10$ & $8 / 7$ \\
\hline $\mathrm{EXCI}(\mathrm{E})$ & & 4 & 9 & 15 & 13 & 15 & $4 / 11$ & $9 / 6$ \\
\hline HABIT & 269 & 1 & 9 & 0 & 0 & 0 & $9 / 6$ & 0 \\
\hline $\mathrm{HAB}(\mathrm{E})$ & & 2 & 5 & 14 & 5 & 8 & $5 / 10$ & $11 / 4$ \\
\hline FLAGIT & 90 & 2 & 4 & 11 & 7 & 1 & $4 / 11$ & $9 / 6$ \\
\hline FLAGR & & 3 & 11 & 0 & 0 & 0 & $10 / 5$ & 0 \\
\hline VENDIT & 54 & 2 & 3 & 14 & 3 & 3 & $3 / 12$ & $1 / 14$ \\
\hline VEND & & 1 & 12 & 14 & 12 & 14 & $12 / 3$ & $13 / 2$ \\
\hline
\end{tabular}

APPENDIX - ROMAN WORKS AND AUTHORS REFERENCED IN THIS PAPER

Caesar, Gaius Julius. c. 100 BCE - 44 BCE. De bello civili.

Catullus, Gaius Valerius. c. 84 BCE - 54 BCE. Carmina.

Cicero, Marcus Tullius. c. 106 BCE - 43 BCE. Epistulae ad Atticum.

Livius (Livy), Titus. c. 59 BCE - 17 CE. Ab urbe condita.

Seneca, Lucius Annaeus. c. 4 BCE - 65 CE. Ad Lucilium epistulae morales and De providentia.

Vergilius (Vergil) Maro, Publius. c. 70 BCE - 19 BCE. Aeneidos. 